\title{
Investigation of active crystal morphogenesis peptide sequences from peptide libraries by crystallization on peptide functionalized beads
}

\author{
Philipp Krattiger ${ }^{\mathrm{a}, 1}$, Nadine Nassif ${ }^{\mathrm{b}, \mathrm{c}, 2,3}$, Antje Völkel ${ }^{\mathrm{b}, 2}$, Yitzhak Mastai ${ }^{\mathrm{d}, 4}$, \\ Helma Wennemers ${ }^{a, 1}$, Helmut Cölfen ${ }^{b, *}$ \\ a Department of Chemistry, University of Basel, St, Johanns-Ring 19, CH-4056 Basel, Switzerland \\ ${ }^{b}$ Max-Planck Institute of Colloids and Interfaces, Colloid Chemistry, Research Campus Golm, D-14424 Potsdam, Germany \\ 'Laboratoire Chimie de la Matière Condensée de Paris, UMR 7574 CNRS, UPMC, Collège de France, 11 place Marcelin Berthelot, 75231 Paris Cedex 05, France \\ d Department of Chemistry, Institute of Nanotechnology, Bar-llan University, Ramat-Gan 52900, Israel
}

Keywords:

Split-and-mix peptide libraries

$\mathrm{CaCO}_{3}$

DL-Alanine

Morphogenesis

Crystallization control

\begin{abstract}
A B S T R A C T
In this study, split-and-mix peptide libraries from one to four amino acids bound to functionalized beads were used to identify active morphogenesis peptides for the systems $\mathrm{CaCO}_{3}$ and DL-alanine. Density gradient ultracentrifugation was used to remove all beads without crystals as well as crystals homogeneously nucleated in solution. From the remaining fractions, beads were selected, which account for differences in crystal morphologies from the default crystal morphology on a micrometer scale and their amino acid sequence was analyzed. Our results show that multiple and different peptide sequences are found to be active in the morphogenesis of $\mathrm{CaCO}_{3}$ and DL-alanine. It was not possible to find a correlation, which connects active single amino acids with the sequences of $\mathrm{di}-$, tri- and tetrapeptides. However peptide charge was found to be important for morphogenesis. Peptides active in $\mathrm{CaCO}_{3}$ morphogenesis were enriched in basic amino acids while those active for DL-alanine morphogenesis contained more acidic amino acids. This can be explained by charge-charge interactions of the crystallizing species with the countercharged peptide moieties. Tests for chiral separation for the DL-alanine system showed that with the applied oligopeptide libraries, no enantioselective crystallization was achieved to a significant extent. The presented combinatorial crystallization assay provides an easy tool for crystallization control, which can be used for the straightforward selection of interesting species under a light microscope. However, suitable staining techniques to identify individual beads with crystals, which are for example a pure enantiomer still need to be developed.
\end{abstract}

\section{Introduction}

Biominerals such as bone, teeth, and shells are highly optimized organic-inorganic hybrid materials with favourable properties and hierarchical order. Their morphology, size, and orientation are driven by local conditions. In particular, the presence of proteins or other macromolecules [1] is found to be essential for the generation of these architectures. It is usually distinguished between insoluble macromolecules like collagen in case of bone or chitin in case of nacre, which build up an organic scaffold for the subse-

\footnotetext{
* Corresponding author. Tel.: +49 3315679513 ; fax: +49 3315679502

E-mail addresses: nadine.nassif@upmc.fr (N. Nassif), mastai@mail.biu.acil (Y.Mastai), Helma.Wennemers@unibas.ch(H.Wennemers), coelfen@mpikg.mpg.de (H. Cölfen).

Fax: +41612670976

2 Tel: +493315679513 ; fax: +493315679502 .

3 Tel: +33 144271434; fax: +33144271504

${ }^{4}$ Tel,: +97235317681 ; fax: +97237384053
}

quent mineralization process (insoluble or structural matrix) and soluble macromolecules, which direct the mineralization process of the inorganic material (soluble or functional matrix).

The processes occurring in vivo in the formation of biominerals are of great interest to material scientists who try to build composite materials and crystalline forms found in nature [2-4]. However, they are very difficult to reveal, as the biopolymers are found as mixtures and they often interact in a synergetic way. Especially soluble biomineralization macromolecules are difficult to analyze, as they are often highly acidic, aggregate and interact with the column material of separation columns so that their purification and characterization is very difficult [5]. Therefore, it is also a useful approach to use synthetic polymers and study their influence onto crystal growth and morphogenesis in order to mimic biomineralization processes and synthesize organic-inorganic hybrid materials with improved properties. A large number of synthetic polymers has been applied in a more or less empirical way for the crystallization control of a large variety of minerals as reviewed in $[6,7]$ and a new class of polymers-the double hydrophilic block 
copolymers $[8,9]$ active in the control of crystal growth was developed inspired by the natural biomineralization polymers, which often exhibit a high amount of acidic residues in blocked sequences [10].

As model for better understanding the control of crystal morphology by biomineralization polymers, previous work has focused on acidic polypeptides such as polyaspartic acid [11-13] or other polyanions [14] as it was shown that acidic matrix proteins or glycoproteins [1] contained in most biominerals are deeply involved in the crystal growth. Indeed, soluble and insoluble protein fractions were shown to regulate crystal growth and control the polymorph in mollusc shells [3]. Further work with simple metal cations [15] and $\alpha, \omega$-dicarboxylic acids [16] on calcium carbonate has shown how small molecules can be used to direct the morphology of calcite crystals. The use of simple amino acids in a specific ratio to the mineral was also shown to be effective to mediate the crystallization of $\mathrm{CaCO}_{3}[17]$.

Another investigation with larger molecules was performed with an $\alpha$-helical peptide designed to bind specific faces of calcite [18] and has highlighted the conformation-dependent control of crystal growth by the secondary structure [19]. Similarly, several macromolecules were found to regulate the morphology of other inorganic crystals. Genetic analysis has identified proteins $[20,21]$ and repeating polypeptides [22] that adhere specifically to inorganic surfaces. In this way, a genetic system in the bacterium Escherichia coli to study the protein-mediated control of gold crystal growth was developed [23]. Peptides displayed by phage have been found to recognize semiconductor surfaces, metal surfaces [24] or precipitate silica by templating the inorganic material [25]. Such phage display libraries have also proven useful for the discovery of peptides that adsorb onto the surfaces of various minerals [26]. However, a drawback is that a peptide, which is actively adsorbing onto a crystal surface, must not necessarily be active in crystallization control with respect to crystal polymorph or morphology control. A recent study has shown that aragonite binding peptides are inhibitors for calcite nucleation when used in a $\mathrm{CaCO}_{3}$ crystallization assay [27].

We envisioned on-bead screening of split-and-mix libraries $[28,29]$ as an alternative combinatorial approach that would allow for directly monitoring the induction of different crystal morphologies. Within split-and-mix libraries, each member of the library is localized on a different bead, thus, different crystal morphologies observed on different beads will be indicative for the influence of the bead bound peptide on either the nucleation or the growth of the inorganic crystal. Such on-bead screenings of split-and-mix libraries have previously not only been used for the identification of selective intermolecular interactions [30] and catalysts [31] but most recently also for the generation of nanometer-sized metal particles [32]

An additional application that can possibly be achieved by crystallization on peptide functionalized beads is chiral resolution. The underlying principle in this approach involves the utilization of peptide functionalized beads as resolving auxiliaries in the crystallization of enantiomers. The hypothesis is that enantiospecific peptide beads will serve as selective chiral nuclei (seeds) during crystallization, lowering the formation energy for crystals of one enantiomer. Consequently, this enantiomer will crystallize in excess on the peptide functionalized beads, thereby enabling separation of this enantiomer from the crystallization solution. The feasibility of this approach was recently demonstrated $[33,34]$ showing that chiral resolution based on enantioselective crystallization on chiral polymeric microspheres is possible. It was demonstrated that chiral microspheres based on poly ( $N$-vinyl-Lphenylalanine) display enantioselective crystallization of $\mathrm{DL}$-valine and provide evidence for crystallization of enantiopure crystals on the chiral surfaces of the polymeric microspheres. With regard

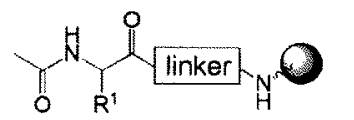<smiles>[R]C(NC(C)=O)C(=O)NC([R])C(=O)C1CC2CCC1C2</smiles>
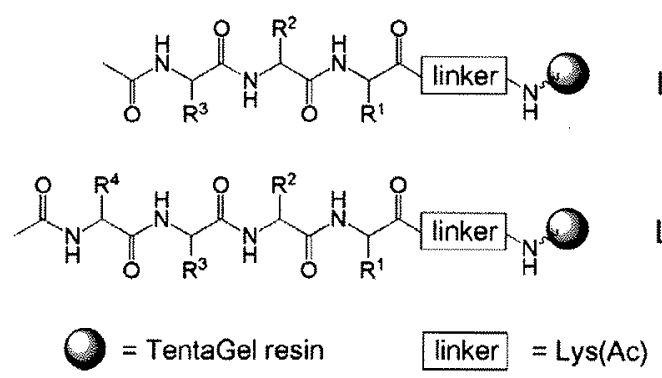

Fig. 1. Four libraries made of single (D- or L-) amino acids (library L1), dipeptides (library L2), tripeptides (library L3) or tetrapeptides (library L4) on TentaGel beads (for the amino acids used, see Section 2).

to chiral resolution the use of polymeric beads with combinatorial chiral peptide libraries opens up the possibility of optimized enantioselective crystallization on chiral polymeric particles, by selection of the optimal chemical chiral functionalities on the surfaces of the polymeric beads.

\section{Experimental}

All chemicals were purchased from Sigma-Aldrich, Senn Chemicals, Merck Biosciences and Bachem.

\subsection{Preparation of the libraries}

The libraries were prepared on TentaGel resin (TentaGel S NH from Rapp Polymere) [35,36] (poly(ethylene glycol) functionalized polystyrene, $0.27 \mathrm{mmol} / \mathrm{g}$ ) using standard conditions to synthesize the linker as well as the peptide library. The encoded $[37,38]$ libraries were synthesized by the split-and-mix protocol $[28,29]$. Using 15 different $\mathrm{D}$ - and $\mathrm{L}$-amino acids in each position (Libraries L1, L2 and L3: AA1 and AA3 = Gly, D-Val, L-Ala, D-Pro, L-Pro, D-Phe, LTyr, D-His, L-Arg, D-Asp, L-Glu, D-Asn, D-Gln, D-Ser, L-Thr; AA2 = Gly, L-Val, D-Ala, D-Pro, L-Pro, L-Phe, D-Tyr, L-His, D-Arg, L-Asp, D-Glu, D-Asn, L-Gln, L-Ser, D-Thr; library L4: AA1 and AA3=Gly, D-Val, L-Ala, L-Leu, D-Pro, L-Pro, D-Phe, L-Tyr, D-His, L-His, D-Arg, D-Asp, L-Glu, D-Asn, L-Gln; AA2 and AA4 = Gly, L-Val, D-Ala, D-Leu, D-Pro, L-Pro, L-Phe, D-Tyr, D-His, L-His, L-Arg, L-Asp, D-Glu, L-Asn, D-Gln.) the dipeptide, tripeptide and tetrapeptide libraries consisted of maximally $15^{2}=255,15^{3}=3375$ and $15^{4}=50625$ members, respectively. After deprotection of the $\mathrm{N}$-terminus the free amines were acetylated and the side chain protecting groups were removed $[39,40]$ (Fig. 1).

\subsection{Crystallization on the beads}

The combinatorial assays were performed by incubating the four different libraries (L1-L4) with saturated aqueous solutions of alanine and calcium carbonate, respectively. A total of at least three theoretical copies of the library were used per screening in order to ensure the presence of each library member $[41,42]$.

Calcium carbonate crystals were grown on the beads by diffusion of carbon dioxide into calcium chloride solutions according to the gas diffusion method [43]. Experiments were performed at 
room temperature $(22 \pm 1 \mathrm{C})$. The aqueous solutions of $\mathrm{CaCl}_{2}$ were prepared in double distilled water and bubbled with $\mathrm{N}_{2}$ overnight before use. Four centrifuge tubes $(5 \mathrm{~mL})$ containing the $0.01 \mathrm{M}$ calcium chloride solution $(4 \mathrm{~mL})$ were mixed, respectively, with the four different libraries (1.4 (L1), 3.2 (L2), 12.5 (L3) and 85.1 (L4) $\mathrm{mg} / \mathrm{mL}$ ) and placed into a closed chamber $\left(3000 \mathrm{~cm}^{3}\right)$ with fresh ammonium carbonate $(3 \mathrm{~g})$. One centrifuge tube containing the calcium chloride solution mixed with non-peptide functionalized TentaGel beads ( $20.2 \mathrm{mg}$ ) was used as reference. The thermal decomposition of ammonium carbonate produced ammonia and carbon dioxide diffusing through one needle hole pierced into the Parafilm cover of the tubes. The initial solution was slightly acidic (pH 5.8) but the $\mathrm{pH}$ rose to 9.5 due to the dissolved $\mathrm{NH}_{3}$. After 5 days, the precipitation was stopped by centrifugation at $3000 \mathrm{rpm}$ for $5 \mathrm{~min}$. The beads were washed twice with the same centrifugation conditions in a saturated calcium carbonate solution in order to avoid crystal dissolution.

For DL-alanine precipitation, the supersaturated alanine solution $(231 \mathrm{mg} / \mathrm{mL})$ was prepared by heating at 60 $\mathrm{C}$ for $1 \mathrm{~h}$. Four centrifuge tubes $(5 \mathrm{~mL})$ containing the supersaturated alanine solution $(4 \mathrm{~mL})$ mixed with the four different libraries (1.4 (L1), 3.2 (L2), 12.5 (L3) and 85.1 (L4) $\mathrm{mg} / \mathrm{mL}$ ) were covered with Parafilm and set under a constant mechanical agitation on an orbital shaker ( $30 \mathrm{rpm})$. One centrifuge tube containing the supersaturated alanine solution and non-peptide functionalized TentaGel beads (20.2 mg) was used as reference. Experiments were performed at room temperature $\left(22 \pm 1^{\circ} \mathrm{C}\right)$. After $15 \mathrm{~h}$, the precipitation was stopped by centrifugation at $3000 \mathrm{rpm}$ for $5 \mathrm{~min}$. The pellets composed of beads were washed twice with the same centrifugation conditions in a saturated alanine solution in order to avoid crystal dissolution. Crystallization was allowed for $15 \mathrm{~h}$. This time was needed to observe (i) well-shaped crystals on the beads, (ii) avoid the complete mineralization of the beads surface which would have hindered identification of the active peptide sequence and (iii) permit to select beads with stable crystals and interesting morphologies.

\subsection{Ultracentrifugation and fractionation}

After crystallization, $3 \mathrm{~mL}$ of saturated calcium carbonate and alanine solution, respectively, were removed and tubes were filled with a sucrose gradient. The separation was performed in an L70 preparative ultracentrifuge (Beckman Coulter, Palo Alto) in a SW55 rotor. For a continuous density gradient $1 \mathrm{~mL}$ of 20,40,50,60 and $67 \%$ sucrose solutions were prepared from water saturated with $\mathrm{CaCO}_{3} .0 .5 \mathrm{~mL}$ sample solution was overlaid and the tubes were run for $24 \mathrm{~h}$ at $39000 \mathrm{rpm}$ to obtain a continuous gradient in the range between 1.100 and $1.312 \mathrm{~g} / \mathrm{mL}$. After ultracentrifugation, the effectivity of the sucrose gradient separation is directly visible by the presence of two thick bead layers (see Fig. 2); the upper one contains beads without crystals and the pellet is composed of the beads bearing crystals.

Control experiments with mineralized beads showed that the ultracentrifugation step does not remove the crystals from the surface of the beads. The supernatant over the discernable noncrystallized bead layer was removed and seven fractions $(\sim 0.7 \mathrm{~mL})$ were transferred into separate Eppendorf tubes with different syringes $(1 \mathrm{~mL})$ starting from the top in order to leave the density gradient undisturbed.

\subsection{Isolation of beads of interest}

Each fraction was deposited on a glass slide and observed by optical microscopy (Nikon Eclipse E600 Pol equipped with crossed polarizers and a DXM $1200 C \mathrm{CD}$ camera and Olympus BX 41 equipped with digital camera). Most of the beads bearing crys-

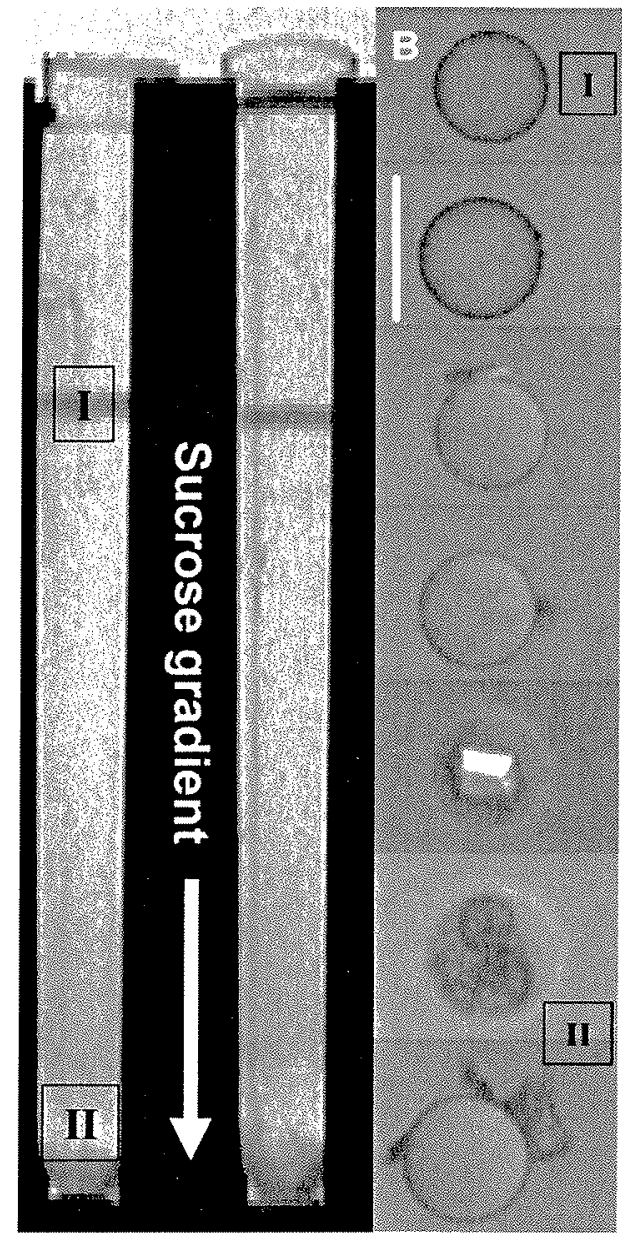

Fig. 2. After the density gradient ultracentrifugation step, the presence of two thick bead layers (I and II) in the centrifugation tubes is observed (A). The upper one contains beads without crystals ( $I$ ) and the pellet is mainly made of beads bearing calcium carbonate crystals (B, scale bar $\sim 150 \mu \mathrm{m}$ ). Several fractions corresponding to different degree of bead mineralization were collected from the top to the bottom as shown in the figure.

tals provided classical rhombohedral calcite crystals but some exhibited unusual morphologies showing the effectiveness of the procedure. Similar considerations are valid for DL-alanine with its default needle shape. The beads with interesting crystal morphologies on them were isolated using an Eppendorf pipette equipped with a gel loading tip and placed individually in microcapillaries for the subsequent peptide analysis. These morphologically active beads are shown together with the nucleated crystal morphologies in Figs. 3 and 4 and SI1 and SI2.

It is important to note that small $\mathrm{CaCO}_{3}$ crystals on beads and empty beads were still observable after 5 days at the same time, proving the specificity of the grafted amino acid or peptide sequences on the different beads as observed in Fig. $5 \mathrm{~A}$. Moreover, to avoid the analysis of peptides grafted on beads where non-specific crystallization occurred, beads possessing two different kinds of crystal morphologies were not collected (Fig. 5B, bead marked with a red dot). Homogeneous nucleation also occurred and led to the precipitation of crystals in the solution which can potentially stick on the beads surface. Slow stirring under the light microscope easily permits to remove them from the beads and avoid the sampling of non-specific peptide-crystal crystallization events. As observed in Fig. 5B and C for example, the observed crystal possesses a spherical morphology but it is birefringent indicating its crystallinity. Thus, this grafted peptide is classified to be 
LIBRARY L1
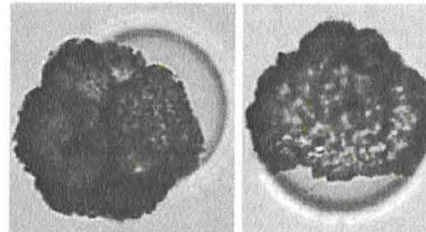

L-Pro

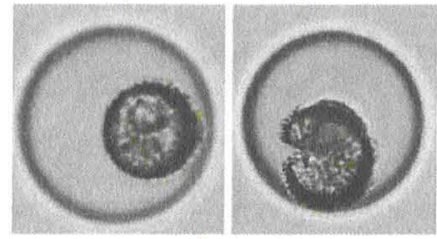

L-Arg

LIBRARY LS
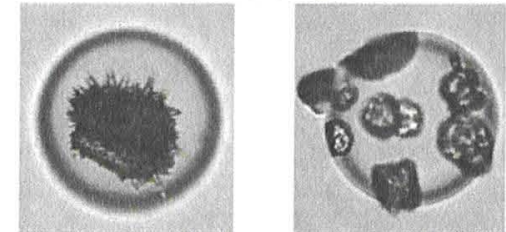

L-Ala-D-Tyr-L-Ala D-Phe-D-Ala-L-Ala

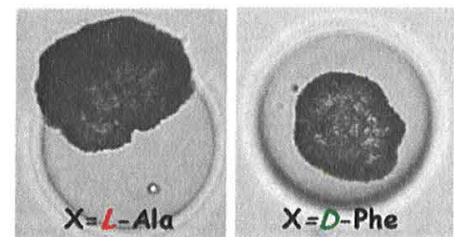

$L-\operatorname{Arg}-L-H i s-X$
LIBRARY L2

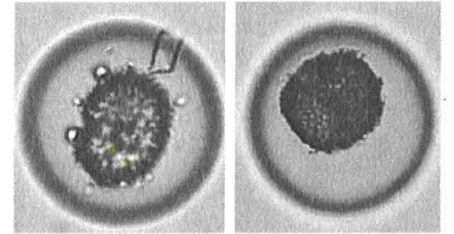

D-Asp-D-Asn

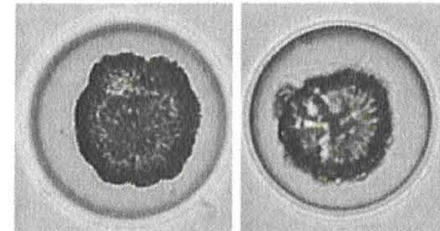

L-Asn-D-Arg
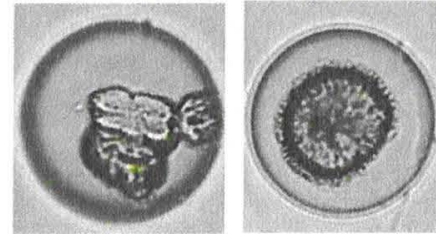

D-pro-D-arg L-pro-D-arg

LIBRARY L4

Fig. 3. Morphologies and the corresponding amino acid sequences for the peptides active in morphogenesis of $\mathrm{CaCO}_{3}$.

interesting as it gives an access to unusual crystalline spherical $\mathrm{CaCO}_{3}$ morphology.

As a control experiment, precipitation of alanine and calcium carbonate was performed on negative control beads bearing simply acetylated amines in place of the peptides (acetylated amino functionalized TentaGel). In a small percentage of cases $(<2 \%)$ adventitious crystals were observed on non-grafted beads presumably due to the presence of cracks formed during the synthesis or handling of the beads before the crystallization reaction (Fig. 6). The rest of the beads remained unchanged and no $\mathrm{CaCO}_{3}$ (resp. alanine) was found in the solution. Isolation of several beads with interesting crystal morphologies deviating from that of the default crystals from both assays $\mathrm{CaCO}_{3}$ and alanine and analysis of the peptides on them revealed a number of morphologically active sequences as listed in the tables in SI3 and SI4.

\subsection{Analysis of chiral discrimination for DL-alanine crystallization}

In a typical crystallization experiment supersaturated DLalanine solution $(200 \mathrm{mg} / \mathrm{mL})$ was prepared and mixed with $3 \mathrm{mg}$ of L2 library and as control experiment DL-alanine was crystallized under identical conditions without the peptide functionalized beads. DL-Alanine crystals crystallized from pure water with a needle-shaped morphology with a relatively uniform crystal thickness and a crystal width of about $20 \mu \mathrm{m}$, and can have a length of up to a few hundred micrometers (see Figure SI5). The kinetics of the crystallization of DL-alanine is relatively slow and typically crystallization is accomplished after ca. $18-24 \mathrm{~h}$. The crystallization kinetics of DL-alanine in the presence of peptides of the library L2 is accelerated relatively to the control experiments and well-defined alanine crystals grew onto the peptide functionalized beads within a few hours as shown by optical microscopy in Figure SI6. For instance after $2 \mathrm{~h}$ ca. $2 \mu \mathrm{m}$ crystals of alanine crystallized on the surfaces of the peptide beads (Figure SI6a) and grew with time, ca. $19 \mathrm{~h}$, to crystals of ca. $60 \mu \mathrm{m}$ (Figure SI6b). It should be mentioned that within an identical time interval crystals were neither observed in the crystallization solution nor in the control experiments. In addition, in those experiments the morphology of the DL-alanine crystals crystallized on the surfaces of peptide functionalized beads is preserved as in the control experiments, namely crystals with needle-shaped morphology. Those results indicate that the peptide functionalized beads promote the crystallization kinetics of DL-alanine and can act as nucleation centers. In order to analyze if enantioselective crystallization has occurred on the surfaces of the peptide functionalized beads we employed a range of methods, e.g. powder $\mathrm{X}$-ray diffraction (XRD) differential scanning calorimetry (DSC) and optical rotation. In a set of crystallization experiments performed at room temperature peptide beads were collected (by centrifugation at $4000 \mathrm{rpm}$ for $3 \mathrm{~min}$ ) after $10 \mathrm{~h}$, and filtered from the crystallization solutions and dried at RT. The peptide functionalized beads where DL-alanine had crystallized were then analyzed. 


\section{LIBRARY L1}

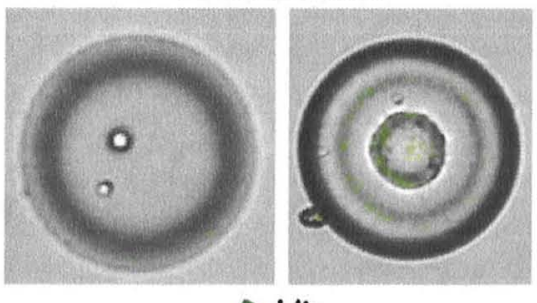

D-His

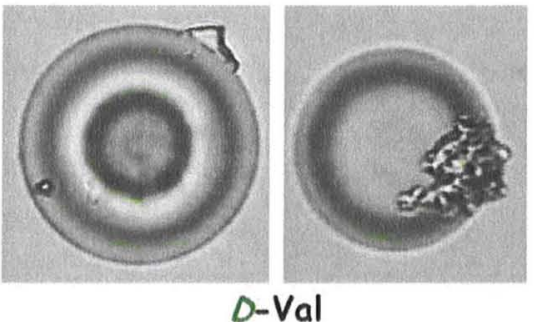

\section{LIBRARY L4}

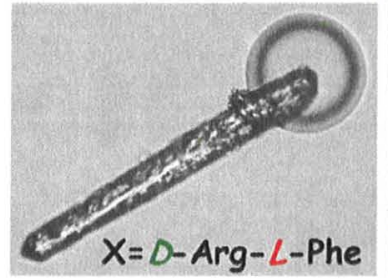

$D$-asp-L-asp- $X$
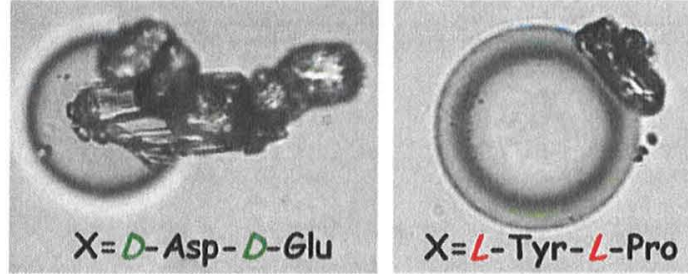

\section{LIBRARY L2}

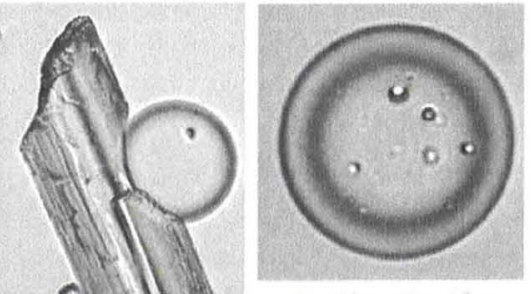

L-Glu-D-Glu

\section{L-Glu-L-Asp}

\section{LIBRARY L3}

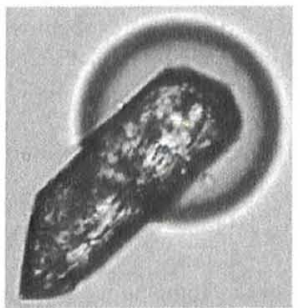

$D-A s p-L-A s p-D-G \ln$

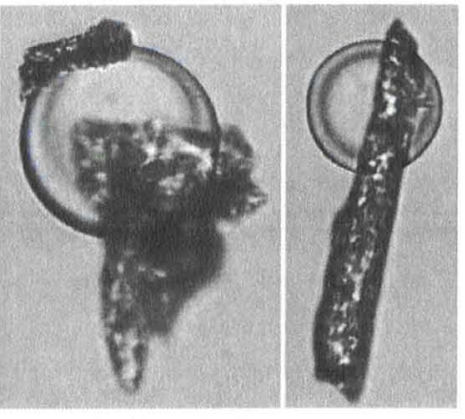

D-Asp-L-Val-L-Asn

Fig. 4. Morphologies and the corresponding amino acid sequences for the peptides active in morphogenesis of DL-alanine.

\section{Results and discussion}

Crystallization of $\mathrm{CaCO}_{3}$ and DL-alanine was possible on the peptide functionalized beads. Figure SI7 shows the example of $\mathrm{CaCO}_{3}$ for the library L3 before separation in the ultracentrifuge.
In the small snapshot, it can be seen that typical rhombohedral calcite crystals of different size are nucleated on most beads, which show double refraction under crossed polarizers. But also, amorphous particles, which appear black under crossed polarizers were observed which becomes even more obvious in the zoom in.

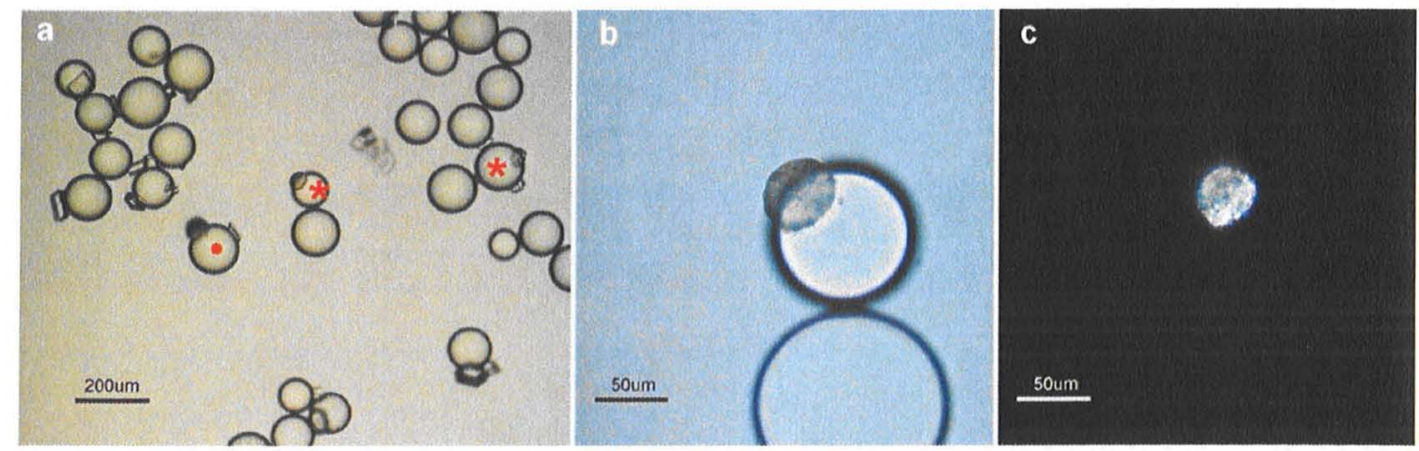

Fig. 5. Precipitations of calcium carbonate on grafted beads with L4: (A) observed by optical microscopy (beads leading to a non-specific crystallization are marked with a red spot and to a specific one with a red star); (B) higher magnification observations of the latter (C) under polarized light microscopy. (For interpretation of the references to colour in this figure legend, the reader is referred to the web version of the article.) 


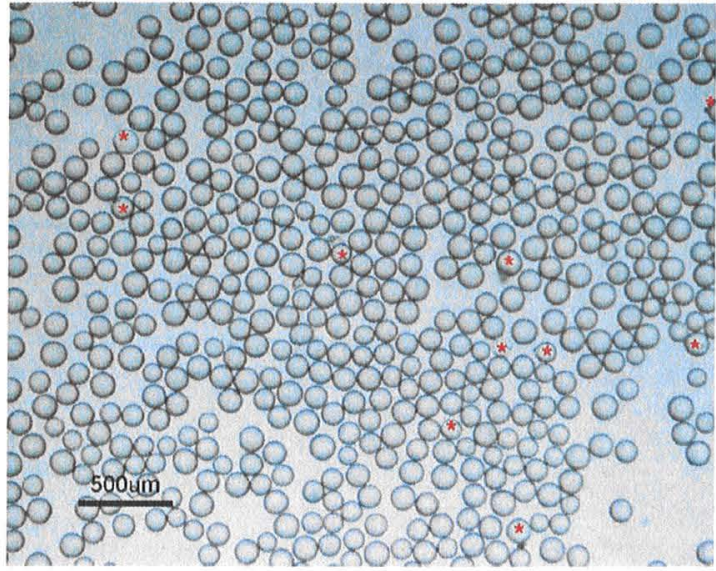

Fig. 6. Precipitation of calcium carbonate on non-grafted beads (Tentagel) observed by optical microscopy. A few crystals on the bead surface (marked with red stars) were observed presumably due to the presence of cracks formed during their synthesis. (For interpretation of the references to colour in this figure legend, the reader is referred to the web version of the article.)

Most particles with morphologies deviating from the typical calcite rhombohedra appear amorphous although crystalline particle assemblies were also found as well as amorphous next to crystalline particles on the beads. Beads with non-uniform precipitates were not selected for the amino acid sequence analysis of the peptides.

Besides the beads with precipitates, a large fraction of the beads remained without crystals on their surfaces and could be removed as a layer after ultracentrifugation. These are all beads, which do not contain a peptide sequence inducing nucleation of a crystal. Although analysis of beads from this layer in principle could reveal peptide sequences for the inhibition of crystallization, the layer of beads without crystals also contains peptide sequences which are inert to crystallization so that no crystal nucleated as is the case for the non-functionalized beads. Therefore the beads without crystals were not further analyzed as a defined correlation of the peptide sequence and crystallization inhibition cannot be made. Similarly, all beads with crystals exhibiting the default crystal morphology (calcite rhombohedron and DL-alanine needle) were not further analyzed, as these peptides are not active in the morphogenesis of unusual crystal morphologies. Finally, we selected a number of 48 beads for $\mathrm{CaCO}_{3}$ and 33 for DL-alanine as shown in Figs. 3 and 4 and SI1 and SI2. The corresponding amino acid sequences are given for the peptides active in morphogenesis of $\mathrm{CaCO}_{3}$ and DL-alanine in SI3 and SI4.

All investigated crystals exhibited a different morphology from each other and the default crystal (Figs. 3 and 4 and SI1-SI4). It can be seen that no clear correlation between the morphologically active L1-L4 peptide generations can be found-neither for $\mathrm{CaCO}_{3}$ nor for DL-alanine. Obviously, there is no correlation in the combination and position of amino acids in a peptide, which will lead to a morphology modification of $\mathrm{CaCO}_{3}$ and DL-alanine. Only individual combinations without obvious correlation are found. A more detailed investigation whether certain types of amino acids are especially active in the morphogenesis process is possible with the tables in the supporting information section (SI3 and SI4). These tables show a colour code for acidic, basic, amides, polar, rigid and apolar amino acids as well as the frequency of the named amino acids found in the morphology modified crystals as compared to the expected frequency by random bead isolation.

If only the type of amino acid and not its position nor the specific side chain are considered but just the type of chemical function, still most of the amino acid types show no correlation between the libraries with respect to amid, polar, rigid, aromatic and apolar amino acids (see SI3 and SI4). However, a correlation becomes obvious for the amino acids with charged side chains (see SI3 and SI4). For $\mathrm{CaCO}_{3}$, for all morphologically active sequences, the frequency of the basic amino acids is much enhanced as compared to the expected frequency (see SI4). This is surprising since usually, acidic proteins are discussed in $\mathrm{CaCO}_{3}$ biomineralization [10] and also in biomimetic mineralization of $\mathrm{CaCO}_{3}$, the usually employed synthetic polymers are anionic [44]. Only a few exceptions with neutral or basic molecules were reported so far for biomineralization [45] or bioinspired mineralization $[46,47]$. This is especially interesting, as the starting pH of the beads solution was 5.8 and then raised to the typical $\mathrm{pH}$ of 9.5 in the gas diffusion reaction. Since the point of zero charge of $\mathrm{CaCO}_{3}$ is around $\mathrm{pH} 8.2$ [48], although starting the mineralization reaction below the $\mathrm{PZC}, \mathrm{CaCO}_{3}$ is negatively charged at the later stages of the gas diffusion mineralization reaction. At this $\mathrm{pH}$, the species appears to be nucleated, which reacts with the basic peptide moieties to form typically amorphous morphologies differing from the typical calcite rhombohedron. Recently, it was found that stable prenucleation clusters are the earliest formed precursor species in $\mathrm{CaCO}_{3}$ crystallization and that these cluster species should be considered for the material transport in $\mathrm{CaCO}_{3}$ crystallization [49-51]. The amount of these clusters dramatically increases with $\mathrm{pH}[49]$ and therefore, it becomes likely that mineral deposition took place above the $\mathrm{PZC}$ of $\mathrm{CaCO}_{3}$ so that due to electrostatic reasons, basic amino acids should be advantageous for interaction, However, it must be underlined again that no defined correlation was found with respect to the exact sidechain and amino acid position.

For DL-alanine, the situation is different (see SI4). Here, the acidic residues were found much more often in morphologically active peptide sequences than expected from the library composition with the exception of the single amino acid library L1. On the other hand, the basic amino acids were found less than expected in the morphologically active sequences, again with the exception of the library L1. The $\mathrm{p} K_{\mathrm{a}}$ of terminal amino groups is usually $>9$, that of alanine specifically $\mathrm{p} K_{\mathrm{a}}=9.87$. This means that DL-alanine offers a positively charged interaction side for the negatively charged acidic peptide residues. On the other hand, with a $\mathrm{p} K_{\mathrm{a}}$ of 2.35 for the carboxy group, an interaction of the basic residues is equally likely.

Overall the charge of an amino acid depends on the isoelectric point $(\mathrm{p} I)$, amino acids become positively charged at $\mathrm{pH}<\mathrm{pI}$, and negatively charged at $\mathrm{pH}>\mathrm{pI}$. Since the isoelectric point of DLalanine is at pH 6.11 [52], and the $\mathrm{pH}$ of the crystallization solution is 5.6, the overall DL-alanine molecule is positively charged at the $\mathrm{pH}$ of the precipitation reaction. It is thus plausible that under those conditions the molecular interactions of DL-alanine with acidic peptide functionalized beads is strong due to charge-charge interactions. This probably leads to high adsorption of DL-alanine to functionalized beads with acidic residues and therefore these peptide beads are active in morphogenesis of DL-alanine.

To test chiral resolution and to look if the peptide functionalized beads can act as selective chiral seeds in the crystallization of DL-alanine, we have performed a series of DL crystallization experiments in the presence of peptides on library L2. The X-ray diffraction spectra of DL-alanine crystallized from pure water and that crystallized on the peptide functionalized beads are shown in Figure SI8. The X-ray diffraction patterns for crystals of pure DL-alanine and crystals on the beads show four main intense diffraction peaks (at $2 \theta=16.27^{\circ}, 20.82^{\circ}, 29.7^{\circ}$ and $33.41^{\circ}$ ) that fit the diffraction pattern of orthorhombic DL-alanine [53] with unit cell constants $a_{0}=12.04, b_{0}=6.04$ and $c_{0}=5.81$ in $\AA$. The X-ray diffraction of Alanine crystallized on the peptide functionalized beads shows two additional diffraction peaks at $2 \theta=27.68$ and 32.20 , which match the diffractions pattern of $(040)$ and (104) crystal planes of pure L- or D-alanine [54]. However, other measurements reveal that DL-alanine does not show enantioselective crystalliza- 
tion on the peptide beads to a significant extent. For example DSC measurements of alanine crystals crystallized on the peptide bead $S$ show a melting point at $260-265^{\circ} \mathrm{C}$ corresponding to pure DL-al anine. In addition optical rotation measurements of the crystallization solutions and of the dissolved alanine crystals showed an enantiomeric excess (e.e.) of $2 \%$ which is negligible. Thus, no enan tiose lective crystallization was observed to a significant extent.

\section{Conclusion and outlook}

Our results show that multiple and different peptide sequences are found to be active in the morphogenesis of $\mathrm{CaCO}_{3}$ and $\mathrm{DL}-$ alanine. It was not possible to find a correlation, which connects active single amino acids with the sequences of $\mathrm{di}^{-}$, tri- and tetrapeptides. This is equally true for the $\mathrm{D}$ - and L-amino acid enantiomers and their combinations in the libraries. Such result reflects the finding that also in biomineralization, usually mixtures of active proteins are found, which makes it hard to isolate individual proteins and investigate their function. For example the proteins, which were extracted from an aragonitic mollusc shell layer and which selectively nucleated aragonite in a subsequent $\mathrm{CaCO}_{3}$ crystallization step were a mixture, which was up to now not identified [3].

This means in turn that a rational design of peptide amino acid sequences for active morphogenesis of crystals is not easily feasible by a step-wise approach starting from a single amino acid and extending the length of the peptide from this. If an active peptide sequence is identified for morphogenesis, it is not possible to deduce that the same sequence shortened or extended by one amino acid will also be active. This hinders the construction of larger peptide sequences with crystal morphogenesis activity.

However, while the exact side chain chemistry and amino acid position showed no correlation between the libraries, the charge of the side chains proved to be of importance for both investigated crystal systems. While basic amino acids showed morphogenesis activity for $\mathrm{CaCO}_{3}$, acidic amino acids were active for the DL-alanine system. This means that in the present case, several possibilities exist to nucleate a different morphology from the default crystal. Charge seems to be the most important parameter for interaction in consistence with a large amount of literature on Biomineralization and bioinspired mineralization, which emphasizes the role of charged macromolecules for mineral deposition.

While no clear correlations between different generations of libraries were found when the morphology selection criterium was applied in this study, the presented combinatorial approach proved to be successful for the identification of peptide sequences which are active in the controlled nucleation of silver colloids of a distinct size in the nm range [32]. In the present study, we selected those crystals with unusual morphology which was polycrystalline or amorphous in case of $\mathrm{CaCO}_{3}$ and often also for alanine. The size of these crystals is in the order of tens of $\mu \mathrm{m}$. Obviously, in this size range, a multitude of different peptides is able to modify the crystal morphology so that no clear correlations become obvious despite that of charge interactions.

The combinatorial split-and-mix library approach is a very simple, versatile and effective way of identifying active peptide sequences for mineralization control, as the results of the crystallization experiment can directly be observed in the light microscope after the uneffective beads have been removed by ultracentrifugation. This allows to search for peptides, which generate a defined morphology. Similar considerations could also apply if peptides for the distinct generation of a certain $\mathrm{CaCO}_{3}$ polymorph like aragonite are required, for example. The fluorescence labelling method reported by Volkmer et al. [55] permits to distinguish between the different polymorphs by their colour in a fluorescence microscope after $\mathrm{Mn}^{2+}$ was added to the crystallization solution.
This could allow for an easy identification of different polymorphs. In analogy, even chiral discrimination might be visualized if an enantiomeric fluorescence dye is applied, which selectively interacts and stains one enantiomer. By that way, peptide sequences might be readily identified, which lead to an enantiomer crystallization from a racemic mixture. The advantage of chiral fluorescence dyes is the possibility to identify even a single bead with crystallized enantiomer, which would not become visible in the here applied methods like XRD, DSC or optical rotation, which rely on average signal for the multitude of components in the mixture. Although we did not yet observe enantioselective crystallization on the surfaces of the peptide functionalized beads due to the applied averaging methods with limited sensitivity, we assume that the use of chiral functionalized beads with a variety of sizes, architectures, and chemical functionalities in the future could provide experimental opportunities for developing a new chiral resolution method based on enantioselective crystallization.

There are further possibilities, which can be imagined to optically distinguish between favourable and unfavourable crystals by optical microscopy either by selective staining methods or polarization microscopy. This shows the large potential of our simple crystallization screening method by combinatorial peptide libraries and will allow for the increase of the knowledge, how crystallization can be directed into a desired direction by peptide additives. This opens the possibility for a better understanding of the interaction of peptides with crystal surfaces or crystallization processes as such.

\section{Acknowledgements}

Tali Menahem and Dana Medina from Bar-llan University are acknowledged for performing parts of the crystallization experiments during a research stay in Golm. We thank the Max-Planck Society for financial support of this work. Y. Mastai would like to thank the Minerva short-term research grants for financial support. Support from the Swiss National Science Foundation and BACHEM is gratefully acknowledged by $\mathrm{H}$. Wennemers.

\section{References}

[1] H.A. Lowenstam, S. Weiner, On Biomineralization, Oxford University Press, New York, 1989.

(2) S. Mann, D.D. Archibald, JM. Didymus, T. Douglas, B.R. Heywood, F.C. Meldrum, N.). Reeves, Crystallization at inorganic-organic interfaces-biominerals and biomimetic synthesis, Science 261 (1993) 1286-1292.

[3] G. Falini, S. Albeck, S. Weiner, L, Addadi, Control of aragonite or calcite polymorphism by mollusk shell macromolecules, Science 271 (1996)67-69.

[4] A. Berman, D.J. Ahn, A. Lio, M. Salmeron, A. Reichert, D. Charych, Total alignment of calcite at acidic polydiacetylene films-cooperativity at the organic-inorganic interface, Science 269 (1995) 515-518.

[5] S. Weiner, Separation of acidic proteins from mineralized tissues by reversedphase high-performance liquid-chromatography. Journal of Chromatography 245 (1982) 148-154.

[6] S.H.Yu, H. Colfen, Bio-inspired crystal morphogenesis by hydrophilic polymers, Journal of Materials Chemistry 14 (2004) 2124-2147.

[7] A.W. Xu, Y.R. Ma, H. Colfen, Biomimetic mineralization, Journal of Materials Chemistry 17 (2007) 415-449.

[8] H. Colfen, Double-hydrophilic block copolymers: synthesis and application as novel surfactants and crystal growth modifiers, Macromolecular Rapid Communications 22 (2001) 219-252.

[9] M.G. Page, N. Nassif, H.G. Borner, M. Antonietti, H. Colfen, Mesoporous calcite by polymer templating, Crystal Growth \& Design 8 (2008) 17921794 .

[10] B.A. Gotliv, N. Kessler, J.L. Sumerel, D.E. Morse, N. Tuross, L. Addadi, S. Weiner, Asprich: a novel aspartic acid-rich protein family from the prismatic shell matrix of the bivalve Atrina rigida, Chembiochem 6 (2005) 304-314. 
[11] A. Wierzbicki, C.S. Sikes, J.D. Madura, B. Drake, Atomic-force microscopy and molecular modeling of protein and peptide binding to calcite, Calcified Tissue International 54 (1994) 133-141.

[12] N. Gehrke, N. Nassif, N. Pinna, M. Antonietti, H.S. Gupta, H. Colfen, Retrosynthesis of nacre via amorphous precursor particles, Chemistry of Materials 17 (2005) 6514-6516

[13] L.B. Gower, Biomimetic model systems for investigating the amorphous precursor pathway and its role in biomineralization, Chemical Reviews 108 (2008) $4551-4627$

[14] S. Albeck, J. Aizenberg, L. Addadi, S. Weiner, Interactions of various skeletal intracrystalline components with calcite crystals, Journal of the American Chemical Society 115 (1993) 11691-11697.

[15] J.O. Titiloye, S.C. Parker, D.J. Osguthorpe, S. Mann, Predicting the influence of growth additives on the morphology of ionic-crystals, Journal of the Chemical Society-Chemical Communications (1991) 1494-1496.

[16] S. Mann, J.M. Didymus, N.P. Sanderson, B.R. Heywood, E.J.A. Samper, Morphological influence of functionalized and non-functionalized-alpha,omegadicarboxylates on calcite crystallization, Journal of the Chemical SocietyFaraday Transactions 86 (1990) 1873-1880.

[17] A.J. Xie, Y.H. Shen, C.Y. Zhang, ZW. Yuan, X.M. Zhu, Y.M. Yang, Crystal growth of calcium carbonate with various morphologies in different amino acid systems, Journal of Crystal Growth 285 (2005) 436-443.

[18] D.B. DeOliveira, R.A. Laursen, Control of calcite crystal morphology by a peptide designed to bind to a specific surface, Journal of the American Chemical Society 119 (1997) 10627-10631.

[19] P. Kasparova, M. Antonietti, H. Colfen, Double hydrophilic block copolymers with switchable secondary structure as additives for crystallization control, Colloids and Surfaces A-Physicochemical and Engineering Aspects 250 (2004) 153-162.

[20] S. Brown, Engineered iron oxide-adhesion mutants of the Escherichia coli phagelambda receptor, Proceedings of the National Academy of Sciences of the United States of America 89 (1992) 8651-8655.

[21] C.F. Barbas, J.S. Rosenblum, R.A. Lerner, Direct selection of antibodies that coordinate metals from semisynthetic combinatorial libraries, Proceedings of the National Academy of Sciences of the United States of America 90 (1993) 6385-6389.

[22] S. Brown, Metal-recognition by repeating polypeptides, Nature Biotechnology 15 (1997) 269-272

[23] S. Brown, M. Sarikaya, E. Johnson, A genetic analysis of crystal growth, Journa] of Molecular Biology 299 (2000) 725-735.

[24] C.E. Flynn, C.B. Mao, A. Hayhurst, J.L. Williams, G. Georgiou, B. Iverson, A.M. Belcher, Synthesis and organization of nanoscale II-VI semiconductor materials using evolved peptide specificity and viral capsid assembly. Journal of Materials Chemistry 13 (2003) 2414-2421.

[25] R.R. Naik, L.L. Brott, S.J. Clarson, M.O. Stone, Silica-precipitating peptides isolated from a combinatorial phage display peptide library, Journal of Nanoscience and Nanotechnology 2 (2002) 95-100

[26] M. Sarikaya, C. Tamerler, A.K.Y.Jen, K.Schulten, F. Baneyx, Molecular biomimetics: nanotechnology through biology, Nature Materials 2 (2003) 577-585.

[27] D. Gebauer, A. Verch, H.G. Borner, H. Colfen, Influence of selected artificial peptides on calcium carbonate precipitation-a quantitative study, Crystal Growth \& Design 9 (2009) 2398-2403.

[28] A. Furka, F. Sebestyen, M. Asgedom, G. Dibo, General-method for rapid synthesis of multicomponent peptide mixtures, International journal of Peptide and Protein Research 37 (1991) 487-493.

[29] K.S. Lam, S.E. Salmon, E.M. Hersh, V.J. Hruby, W.M. Kazmierski, RJ. Knapp, A new type of synthetic peptide library for identifying ligand-binding activity, Nature 354 (1991) 82-84

[30] N. Srinivasan, J.D. Kilburn, Combinatorial approaches to synthetic receptors, Current Opinion in Chemical Biology 8 (2004) 305-310.

[31] J.D. Revell, $H$. Wennemers, Peptidic catalysts developed by combinatorial screening methods, Current Opinion in Chemical Biology 11 (2007) 269278.

[32] K. Belser, T.V.Slenters, C. Pfumbidzai, G. Upert, L. Mirolo, K.M. Fromm, H. Wennemers, Silver nanoparticle formation in different sizes induced by peptides identified within split-and-mix libraries, Angewandte Chemie-International Edition 48 (2009) 3661-3664.
[33] D.D. Medina, J. Goldshtein, S. Margel, Y. Mastai, Enantioselective crystallization on chiral polymeric microspheres, Advanced Functional Materials 17 (2007) 944-950.

[34] T. Menahem, Y. Mastai, Chiral soluble polymers and microspheres for enantioselective crystallization, Journal of Polymer Science Part A-Polymer Chemistry 44 (2006) 3009-3017.

[35] E. Bayer, Auf dem Weg zur chemischen Synthese von Proteinen, Angewandte Chemie 103 (1991) 117-132.

[36] E. Bayer, Towards the chemical synthesis of proteins, Angewandte ChemieInternational Edition in English 30 (1991) 113-129.

[37] M.H.J. Ohimeyer, R.N. Swanson, L.W. Dillard, J.C. Reader, G. Asouline, R Kobayashi, M. Wigler, W.C. Still, Complex synthetic chemical libraries indexed with molecular tags, Proceedings of the National Academy of Sciences of the with molecular tags, Proceedings of the National Aca

[38] H.P. Nestler, P.A. Bartlett, W.C. Still, A general-method for molecular tagging of encoded combinatorial chemistry libraries, Journal of Organic Chemistry 59 (1994) $4723-4724$.

[39] P. Krattiger, C. McCarthy, A. Pfaltz, H. Wennemers, Catalyst-substrate coimmobilization: a strategy for catalysts discovery in split-and-mix libraries, Angewandte Chemie-International Edition 42 (2003) 1722-1724

[40] P. Krattiger, R. Kovasy, J.D. Revell, S, Ivan, H. Wennemers, Increased structural complexity leads to higher activity: peptides as efficient and versatile catalysts for asymmetric aldol reactions, Organic Letters 7 (2005) 1101-1103.

[41] K. Burgess, A.I. Liaw, N.Y. Wang, Combinatorial technologies involving reiterative division/coupling/recombination-statistical considerations, Journal of Medicinal Chemistry 37 (1994) 2985-2987.

[42] P.L.Zhao, R. Zambias, J.A. Bolognese, D. Boulton, K. Chapman, Sample-size determination in combinatorial chemistry, Proceedings of the National Academy of Sciences of the United States of America 92 (1995) 10212-10216.

[43] L. Addadi, J. Moradian, E. Shay, N.G. Maroudas, S. Weiner, A chemicalmodel for the cooperation of sulfates and carboxylates in calcite crystal nucleation-relevance to biomineralization. Proceedings of the National Academy of Sciences of the United States of America 84 (1987) 2732-2736.

[44] $\mathrm{H}$. Colfen, From biomineralization polymers to double hydrophilic block and graft copolymers, in: K.G. Matyjaszewski, Y. Gananou, L. Leibler (Eds.), Macromolecular Engineering: Precise Synthesis, Materials Properties, Applications, Wiley-VCH, Weinheim, 2004.

[45] K. Mann, F. Siedler, L. Treccani, F. Heinemann, M. Fritz, Perlinhibin, a cysteine, histidine-, and arginine-rich miniprotein from abalone (Haliotis laevigata) nacre, inhibits in vitro calcium carbonate crystallization, Biophysical Journal 93 (2007) 1246-1254

[46] K. Kim, A. Uysal, S. Kewalramani, B. Stripe, P. Dutta, Effects of chitosan on the alignment, morphology and shape of calcite crystals nucleating under Langmuir monolayers, Crystengcomm 11 (2009) 130-134.

[47] J.W. Xiao, Y.C. Zhu, Y.Y, Liu, H. Liu, Y. Zeng, F.F. Xu, LZ Wang, Vaterite selection by chitosan gel: an example of polymorph selection by morphology of biomacromolecules, Crystal Growth \& Design 8 (2008) 2887-2891.

[48] M.F. Salinas-Nolasco, J. Mendez-Vivar, V.H. Lara, P. Bosch, Passivation of the calcite surface with malonate ion, Joumal of Colloid and Interface Science 274 (2004) 16-24.

[49] D. Gebauer, A. Volkel, H. Colfen, Stable prenucleation calcium carbonate clusters, Science 322 (2008) 1819-1822

[50] E.M. Pouget, P.H.H. Bomans, J. Goos, P.M. Frederik, G. de With, N. Sommerdijk, The initial stages of template-controlled $\mathrm{CaCO}_{3}$ formation revealed by $\mathrm{Cryo-}$ TEM, Science 323 (2009) 1455-1458.

[51] F.C. Meldrum, R.P. Sear, MATERIALS SCIENCE now you see them, Science 322 (2008) 1802-1803.

[52] R.C. Weast, Handbook of Chemistry and Physics, CRC Press, Cleveland, OH, 1973 , p. C741.

[53] J. Donohue, The crystal structure of DL-alanine. II. Revision of parameters by three-dimensional Fourier analysis, Journal of the American Chemical Society 72 (1950) 949-953.

[54] H.]. Simpson, R.E. Marsh, Crystal structure of $L$-alanine, Acta Crystallographica $20(1966) 550$.

[55] D. Volkmer, M. Fricke, C. Agena, J. Mattay, Interfacial electrostatics guiding the crystallization of $\mathrm{CaCO}_{3}$ underneath monolayers of calixarenes and resorcarenes, Journal of Materials Chemistry 14 (2004) 2249-2259. 